\title{
SEXUAÇÃO, DESEJO E GOZO: ENTRE NEUROSE E PERVERSÃO'
}

\author{
Sonia Alberti \\ Maria Helena Martinho
}

Resumo: Este artigo retoma três perguntas lançadas por Freud em 1927, no seu excepcional texto intitulado "Fetichismo", para repensá-las a partir do ensino de Lacan dos anos 1970, conhecido como o campo do gozo. O artigo se serve das fórmulas quânticas da sexuação, para verificar a evidenciação lógica "a relação sexual não existe" na posição sexuada que um sujeito pode ocupar com seus parceiros nas estruturas neurótica e perversa. Interrogamos algumas variantes do sujeito com seu parceiro no gozo e no desejo. Para tanto, retomamos os três tipos de gozo verificados por Lacan na relação do sujeito com o parceiro na posição sexuada: o gozo feminino - também chamado de suplementar e gozo Outro -, o gozo místico e o gozo perverso. Revisitam-se os casos trabalhados por Lacan para questionar o que distingue fundamentalmente o neurótico do perverso, ou seja, retomando as questões introduzidas por Freud.

Palavras-chave: Sexuação. Desejo. Gozo. Neurose. Perversão.

\section{Introdução}

Em 1927, no texto que intitulou "Fetichismo", Freud lançou três perguntas: "por que alguns [homens] se tornam homossexuais em consequência do horror da castração? Por que outros se defendem do horror da castração criando um fetiche? Por que a imensa maioria supera o horror da castração?" (Freud, 1927/2004, p.

1 Artigo elaborado a partir da Tese de Doutorado de Maria Helena Martinho que teve Sonia Alberti como co-orientadora, defendida em janeiro de 2011 no Programa de Pós-graduação em Psicanálise/IP/UERJ. 
149). Poderíamos desmembrá-las nas seguintes formulações: como um homossexual, um perverso e um neurótico respondem ao "não há relação sexual"? Quais seriam as escolhas desses sujeitos quanto às posições sexuadas que ocupam com os seus parceiros sexuais? De saída, é importante observar que as três perguntas de Freud não especificam a estrutura dos sujeitos, razão de, no desmembramento proposto, não haver essa especificação, tampouco no que tange à escolha pela homossexualidade que certamente não está ligada a nenhuma estrutura psíquica, somente à posição do sujeito diante do objeto. Na expectativa de aprofundar tais questões, tomaremos aqui as fórmulas quânticas da sexuação, pois, além de elas serem a evidenciação lógica de que "a relação sexual não existe", permitem verificar a posição sexuada que o sujeito pode ocupar com seus parceiros sexuais nas estruturas neurótica e perversa, ou seja, sempre que a não existência da relação sexual se impõe ao sujeito.

Logo de início, lembramos que ao afirmar "não há relação sexual", Lacan não está dizendo em absoluto que não há ato sexual, desejo sexual ou amor, mas está evidenciando que não há complementaridade lógica entre os sexos ou, como a fórmula é traduzida em língua espanhola,"não há proporção sexual"."O não há relação sexual, não implica que não haja relação ao sexo. É justamente o contrário, isso o que a castração demonstra, quer dizer, que essa relação ao sexo seja distinta em cada metade, pelo fato mesmo de reparti-las" (Lacan, 1973/2003, p. 464) - as metades aqui aludidas são aquelas que Lacan inscreveu nas fórmulas quânticas da sexuação, como veremos. Tal observação de Lacan nos orienta para o fato de que, nem na neurose e nem na perversão, é possível encontrar, via amor, a cara metade - expressão que usamos aludindo ao mito aristofânico (Freud, 1920/2006).

Se o outro sexuado, a outra pessoa com quem alguém se relaciona na relação sexual, pode ser o seu parceiro no amor, nós perguntamos: Quais seriam as variantes do parceiro da relação com o gozo?

\section{A parte superior das fórmulas quânticas da sexuação.}

Apesar de Lacan ter começado a notação das fórmulas antes, as nomeia como fórmulas quânticas da sexuação somente em "O Seminário", livro 21, Os não tolos erram. Na psicanálise, a identidade sexual não depende da anatomia e sim, do que Lacan qualificou de "sexuação". Para demonstrá-la, Lacan apresenta quatro fórmulas proposicionais: duas à esquerda e duas à direita. Ele distribui os seres em duas categorias: aqueles que estão todos na função fálica e aqueles que não estão todos nesta função. A partir do caráter binário de "para todo $x$ " ou "não todo $x$ ", aquele que está "todo" na função fálica, é chamado homem; aquele que está "não 
todo" na função fálica, é chamado mulher, qualquer que seja a sua anatomia. Isto vai ao encontro do que Lacan já conceituara sobre a fantasia, que Freud definiu como sexual. Ao articular a relação do sujeito com o objeto de sua fantasia no matema $\$<>a$, ele já identificara todo sujeito desejante do lado homem que, como também Freud (1905/2005b) conceituara, busca na mulher seu objeto ou parceiro, ocupando para o sujeito, o lugar do objeto teorizado por Lacan como $a$.

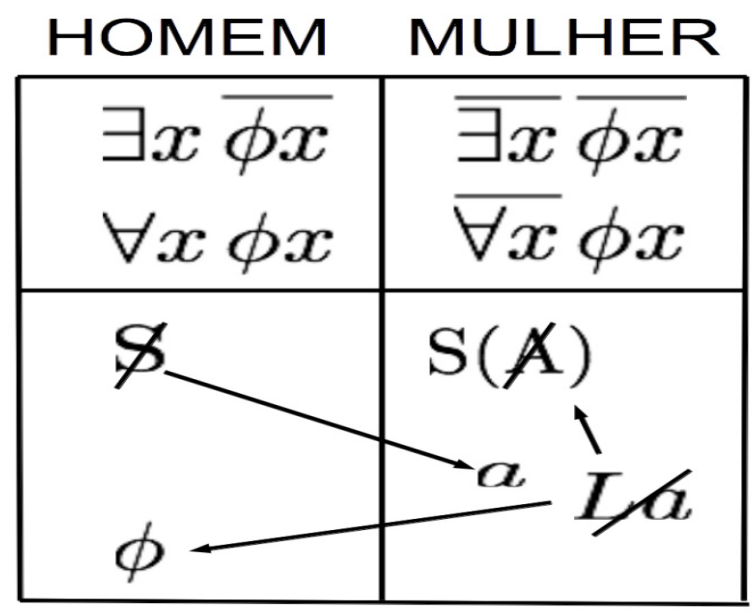

Figura 1. Grafo das fórmulas quânticas da sexuação conforme Lacan (1972-1973/1976, p. 73).

Do lado homem encontramos a função universal do falo, todos os homens estão na função fálica, mas para que essa proposição universal seja verdadeira, é necessária uma exceção que confirme a regra: ao menos um não é castrado. Essa exceção é sustentada pelo "Pai da horda primeva" (Freud, 1912-1913/2005c), o único a ter direito a gozar da mulher e que proibia a todos os filhos gozar do Outro sexo. O ao menos Um não castrado, permite fazer existir o conjunto de todos os homens, referidos ao falo, todos são castrados. Porém, aquele Pai foi morto e, uma vez morto, foi substituído pelo totem que o representa e que permite que todos possam desejar, pois a ele está atrelada a função simbólica da lei, garantia do acesso ao desejo: ao interditar o incesto, garante ao mesmo tempo, que os filhos totêmicos possam aceder a pelo menos uma mulher que não esteja interditada.

Do lado direito das fórmulas, o lado mulher não há conjunto, pois não existe ao menos uma que não seja castrada. Tal fundamentação vem do outro lado, o lado homem, razão de Freud já ter estipulado desde sempre a anterioridade do homem na constituição do sujeito do desejo. Para situar-se do lado mulher, foi necessário ter passado primeiro pela referência univer- 
sal do "todos são castrados" e que se encontra do lado homem. Com efeito, não há mulher que não tenha passado pela fase fálica (fase Édipo) - lembremo-nos o quanto Freud insistiu nisso contra, por exemplo, Jung que quis atribuir um complexo de Electra à mulher -, ou seja, que não tenha ela também se identificado do lado homem da sexuação. Porém, as mulheres não estão inteiramente inscritas na função fálica. A mulher é"não toda fálica", o que define a posição feminina. E como é a referência fálica que universaliza os seres falantes, os faz existir - no sentido cartesiano mesmo do termo - como seres falantes, $A$ mulher não existe, as mulheres se contam uma a uma, ao contrário dos homens, elas são não-todas.

\section{A parte inferior das fórmulas quânticas da sexuação.}

Na parte inferior das fórmulas quânticas da sexuação (ver figura 1), Lacan representa os lados homem e mulher mediante setas, indicando o que cada um busca do lado do parceiro:

\section{Do lado homem encontra-se:}

\$: sujeito - sempre dividido, e $\Phi$ : Falo.

\section{Do lado mulher encontra-se:}

$L d^{2}$ : A mulher - sempre barrada por não existir; $S(\mathbb{A})$ : significante da falta no Outro, e $a$ : objeto $a$.

Do lado homem: Se todo sujeito deseja a partir de sua referência ao falo, objeto do desejo por definição, a seta que vai do \$ (no lado homem) até $a$ (no lado mulher) descreve o fato que ao desejar, todo sujeito desejante independente de seu sexo biológico, está do lado homem. Ele visa reencontrar no lugar de seu parceiro o objeto $a$, causa de seu desejo. Representado nas fórmulas quânticas da sexuação, o sujeito referido ao falo enquanto falta, busca o objeto de sua fantasia. E a causa do desejo, ele visa enquanto Outro sexo."Só lhe é dado atingir seu parceiro sexual, que é o Outro, por intermédio disto, de ele ser a causa de seu desejo" (Lacan, 1972-1973/1985, p. 108), já que, para o macho - Lacan (1972-1973/1985, p. 98 , sic) -, o objeto $a$ faz"o papel do que vem em lugar do parceiro que falta [e é em que constitui] o que costumamos ver surgir também no lugar do real, isto é, a fantasia" (Lacan, 1972-1973/1985, p. 85). Ou seja, na relação do sujeito para com o parceiro do desejo, as fórmulas quânticas da sexuação retomam o desenvolvimento que Lacan (1966-1967) fizera

2 Lá: mantivemos a notação francesa proposta por Lacan (1972-1973/1985) que especifica 0 artigo feminino da mulher em francês La femme, para deixar clara a especificidade dessa notação. A versão do "Seminário" em português traduz esse artigo na notação A, o que pode levar a uma confusão com a notação do Outro, conceito de Lacan. 
ao proferir em seu seminário sobre a lógica da fantasia, que a fantasia se compõe de $\$<>a$ - todas as relações do sujeito com o objeto $a$.

O homem, diz Lacan, crê que aborda a mulher, mas o que ele aborda é a causa do desejo dele (a). "Aí está o ato de amor. Fazer amor é poesia. Mas, há um mundo entre a poesia e o ato. $O$ ato de amor é a perversão polimorfa do macho" (Lacan, 1972-1973/1985, p. 98).Dois seminários depois, Lacan confirma e conclui que esse é o sintoma do homem. Se A Mulher não existe - como vimos, ela é sempre não toda -, no lugar dela o homem vai colocar "uma mulher", como um sintoma.

Do lado da mulher: são duas as setas que se orientam a partir de $L a$ - forma de Lacan inscrever nas fórmulas $A$ Mulher que não existe. Cada qual segue em uma direção: a seta que vai de $L \not ́$ até $\Phi$, descreve a problemática fálica da relação da mulher com o homem, por portar a referência fálica "o homem não é mais que um significante. Uma mulher busca um homem a título de significante" (Lacan, 1972-1973/1985, p. 49). Ora, o significante que representa o homem é o falo. Para se sentir amada, a mulher necessita que o homem sinta desejo sexual por ela, razão, aliás, de ela se fazer desejar por ele. Dez anos antes Lacan observava:

A mulher revela-se superior no campo do gozo, uma vez que seu vínculo com o nó do desejo é bem mais frouxo. A falta, o sinal menos com que é marcada a função fálica no homem, e que faz com que sua ligação com o objeto tenha que passar pela negativização do falo e pelo complexo de castração, o status do menos fi no centro do desejo do homem, é isso que não constitui, para a mulher, o nó necessário. (Lacan, 1963/2005, p. 202)

Se ainda supunha um desejo à mulher, em 1963, mesmo que frouxo, em 1973 claramente coloca Lá mulher do lado da que não tem o que perder, que portanto não deseja. Então esta seta que vai de $L \mathscr{a}$ até $\Phi$, diz respeito justamente ao movimento ao qual, $A$ Mulher que não existe busca sua afirmação, em um dizer, a partir do desejo de um homem por ela. Em 1963, Lacan chega a dizer que a mulher visa no homem a tumescência, prova do desejo dele por ela. Não significa dizer que é ela que o deseja, mas sim, que justamente por não desejar enquanto $L a$, que ela o ama. Enquanto sujeito ela deseja, mas aí ela não está do lado mulher e sim do lado homem.

A outra seta, a que vai de $L a$ até $S(\mathbb{A})$, designa a parte do ser feminino que não diz respeito à função fálica, e que, como vimos, faz com que a mulher seja não-toda. É aqui que Lacan inscreve um gozo para além do falo, também chamado de gozo feminino e de Outro gozo, um gozo suplementar. "É justamente pelo fato de que, por ser não-toda, ela tem, em relação ao que a função fálica designa como gozo, um gozo suplementar" (Lacan, 1972-1973/1985, p. 108). Desde cedo em seu ensino, Lacan havia definido, com seu estudo do cógito cartesiano, que o que existe, existe no 
simbólico e que o que está fora do simbólico, ex-siste (siste fora), está no real. Ora, o que tem significação - no sentido da Bedeutung - é referido ao falo enquanto significante, o falo simbólico (Lacan, 1958/1998b), de forma que quando se trata de um gozo suplementar, necessariamente estamos fora da referência simbólica do falo, estamos no real. Daí a impossibilidade de saber o gozo feminino. Encontramos também na indicação dessa segunda seta, nesse lugar opaco do Outro gozo, o gozo místico. Ele se aproxima do gozo feminino, pois "na medida em que seu gozo é radicalmente Outro que a mulher tem mais relação com Deus" (Lacan, 1972-1973/1985, p. 111). Nem o gozo feminino nem o místico podem ser verificados porque é impossível saber sobre os mesmos.

De todo modo, há que observar que somente quando a teoria chega a esse momento de sua formulação que podemos efetivamente colocar a questão sobre o gozo. Do lado homem, desejo e gozo se confundem por ambos estarem referidos à norma fálica. É o lado mulher que introduz a disjunção. Se ela deseja, está do lado homem como sujeito, quando está do lado mulher não deseja, goza. Ao colocar a questão já introduzida em $1925^{3}$ por Freud, “O que quer uma mulher?", que a psicanálise, avançando, coloca a questão sobre a disjunção entre desejo e gozo.

Como vimos, $A$ Mulher, do lado do não-todo fálico, se divide entre a relação com o Falo $(\Phi)$ e outra com $S(\mathbb{A})$. A primeira orienta-se para o gozo fálico, fora do corpo (Lacan, 1972-1973/1985, p. 109), em função do que Freud (1933[1932]/2004) já identificava como desejo de pênis, ou melhor, como foi tão bem traduzido para o inglês, penis envy - inveja do pênis que, em inglês, também é desejo de pênis. Tal envy é a busca dela por uma representação, como o homem tem a partir de sua referência fálica. Não se expressando de outra maneira, Freud observou um "desejo de pênis", que o deixou em "maus lençóis" com as feministas de sua época. O associamos com a observação de Lacan já citada acima, de que $L, a ́$ Mulher deseja a referência ao significante dada pelo homem. A segunda, a relação $\operatorname{com} S(\mathbb{A})$, orienta-se para um gozo muitas vezes dito como sendo "no corpo todo", ao contrário do fálico, gozo fora do corpo, é um Outro gozo, outro por ser não fálico, dito pelas mulheres "no corpo todo." Mas não há significante que permita referi-lo, e é por essa razão, que Lacan o aproxima de um gozo "enigmático" ou "louco".

O gozo do homem.

Ao introduzirem a questão do gozo por via do gozo feminino, as fórmulas quânticas da sexuação questionam, também, sobre o gozo do

3 Conforme relatado por Jones (1955, p. 468), a partir de uma conversa de Freud com Marie Bonaparte, em 1925. 
homem. É aqui que levantamos a questão sobre o gozo do sujeito. Abordando a questão pelo viés da distinção entre o gozo feminino e o fálico que, em oposição àquele, é fora do corpo, aludimos ao fato de que falicamente goza-se com a palavra, por exemplo, nos chistes, na pornografia e na significação fálica.

Se não significa dizer que o homem não goze com o corpo, para o que bastaria estar do lado mulher nas fórmulas quânticas, é difícil articular o gozo do sujeito do lado homem devido ao encontro com uma mulher. As dificuldades disso são patentes na clínica, por exemplo, como impotência psíquica. Esta, já fora definida por Freud em sua trilogia da vida amorosa, quando distinguia a impotência por questões orgânicas da psíquica, aquela que impede o sujeito de gozar de uma mulher em função da dificuldade de se posicionar como homem diante dela (Freud, 1912/2004). Com efeito, todo encontro com uma mulher introduz, para o sujeito estruturado conforme a neurose, independente de este ser homem ou mulher, uma heteronímia, baseada na impossibilidade da completude, na falta, na carência de simbolização, quando não o Unheimliche (Freud, 1919/2006), o íntimo não familiar. De algum modo, sempre que se está do lado homem e que se procura o Outro sexo para a obtenção de gozo, sempre que o gozo na relação sexual é corporal e, por isso, gozo do Outro, estrangeiro ao sujeito, sempre se encontra uma inadequação. E para não arriscar perder-se quando se vai ao encontro do Outro sexo, é preciso fazê-lo de maneira perversamente orientada - Lacan faz aqui um jogo de palavras na língua francesa, a père version, orientado conforme a versão dada pelo pai que implica a castração. Quando o sujeito está perversamente orientado, faz do Outro sexo o objeto $a$, parte inferior das fórmulas quânticas da sexuação, no vetor que vai do sujeito (lado homem) ao objeto a (lado mulher), tomando a mulher como objeto causa de desejo. O gozo do Outro tomado como corpo é assim inadequado ao sujeito - referido ao gozo fálico que, como vimos, é fora do corpo -, razão pela qual ele se orienta perversamente. Na verdade, os neuróticos não possuem nenhum dos caracteres do perverso, apesar de sonharem com eles"o que é bem natural, pois sem isso, como atingir o parceiro?" (Lacan, 1972-1973/1985, p. 116).

\section{Variações nas fórmulas:entre neurose e perversão universal.}

Retomamos neste subtítulo, a fórmula proposta no título desse artigo, que relaciona alternativamente neurose e perversão. Se a conjunção "ou" o exprimiria de maneira exata, já que ela é tanto indecidível quanto implica a incompatibilidade, optamos por utilizar a preposição "entre" porque a associamos à expressão freudiana, segundo a qual o impossível 
leva a nos depararmos com o que a mitologia exprime na relação entre Cila e Caríbdis (Freud, 1932[1933]/1969, p. 578).

O campo do gozo já não parte da distinção das estruturas clínicas, como é o caso do campo da fala e da linguagem que estrutura a relação com o desejo - edípico por definição -, ou seja, que diz respeito à escoIha do sujeito diante da castração - Verdrängung (recalque), Verleugnung (desmentido) e Verwerfung (foraclusão). O campo do gozo permite, por exemplo, perguntar: se tomamos um sujeito, do lado esquerdo das fórmulas, quais seriam os parceiros possíveis? Pode ser uma mulher, um homem, um fetiche e até Deus.

A tese de Lacan vem problematizar que o homem, o qual está todo na função fálica, tem por parceiro o objeto $a$ da fantasia. Conforme o caso, entre um homem e uma mulher, entre um homem e outro homem e entre um homem e Deus, pode haver interposição de gozo que arrasta consigo a fantasia. Desde 1905, podemos dizer com Freud que essa perversão universal está no cerne da fantasia (Freud, 1905/2005b, p. 211), ou que toda sexualidade humana é perversa (Freud, 1905/2005b; Lacan, 1975-1976/2007), isto para o desejo.

Nossa hipótese é que um ser falante irá se alinhar ou do lado homem ou do lado mulher das fórmulas, independente do sexo anatômico, de modo que a distinção feita por Lacan entre o todo fálico e o não-todo fálico corresponde a seu modo de gozo.

Para verificá-la, retomemos mais detalhadamente, três tipos de gozo demonstrados por Lacan nas fórmulas quânticas da sexuação: o gozo feminino - também chamado de gozo suplementar e de gozo Outro -, o gozo místico e o gozo perverso, especificando a posição que o sujeito ocupa diante de seus parceiros nessas modalidades de gozo. Observamos que não pretendemos excluir outras formas de gozo passíveis de serem depreendidos das fórmulas, o que deixaremos para trabalhos posteriores.

Como vimos, o gozo feminino está em $S(\mathbb{A})$, que se distingue por não dizer respeito à função fálica. Lacan nos ensina que estar no lugar da não-toda faz a mulher ausente de si mesma enquanto sujeito (Lacan, $1972-1973 / 1985$, p. 49). No que tange ao gozo feminino, Lá não frequenta o lado esquerdo das fórmulas quânticas da sexuação. Seria, nesse caso, seu parceiro sua própria ausência de si mesma?

O gozo místico também está em $S(\mathbb{A})$. Este gozo é ilustrado por Lacan a partir de duas mulheres: Hadewijch d'Anvers, uma beata Beguina, e Santa Teresa d'Avila. Hadewijch viveu no século XIII, tendo pertencido à Ordem da Beguina, criada por si própria. Aos dezenove anos teve sua primeira visão em que testemunhou revelações espirituais através de um anjo. Experimentava a presença divina que chamou de "a face de Deus" e julgou compreender o sentido da Divina-humanidade sobre o que escrevia em seus poemas (cf. Martinho, 2011). Santa Teresa nasceu em Ávila, Espanha, em 1515 e faleceu em 1582. Criou a Reforma Carmelita e restau- 
rou a austeridade e o caráter contemplativo da vida carmelita primitiva. Foi canonizada em 1622 e foi elevada a Doutora da Igreja em 1970 pelo Papa Paulo Vl, primeira mulher a ser assim homenageada. Seus escritos místicos se baseavam em suas experiências de gozo mundano - até 1563 os religiosos não eram obrigados à clausura - que ela associou às visões. Foi retratada por Bernini - nascido quatro anos depois da morte da Santa - em escultura em um nicho da Igreja de Santa Maria della Vittoria, na qual se vê materializado o êxtase de Santa Teresa que a Igreja Católica preferia esconder - escultura que ilustra a capa de O Seminário, livro 20: Mais ainda, de Lacan que, sobre isso, diz: "Basta vocês olharem em Roma a estátua de Bernini para compreenderem logo que ela está gozando" (Lacan, 1972-1973/1985, p. 103). Um gozo "enigmático" ou "louco" (p. 197), que aproxima o gozo feminino ao gozo místico. Para Lacan, tanto a beata como a Santa ocupam a mesma posição sexuada diante do parceiro-Deus. Por se tratar de um gozo "louco" ou "enigmático", permanece do lado direito das fórmulas quânticas da sexuação, o parceiro de ambas no lugar de $L A$, está em $S(\mathbb{A})$.

Para Lacan, o gozo místico pode se presentificar tanto naqueles que estejam posicionados no não-todo fálico - caso da Santa e da beata - como nos que estejam no todo fálico. Ele ilustra sua tese tomando como exemplo San Angelus Silesius. Místico nascido na Polônia em 1624, médico e poeta religioso, ordenado sacerdote no ano de 1661 em Breslau onde nasceu, Johannes Scheffler escrevia sob o nome monástico de Angelus Silesius. O crítico Georg Ellinger observa, em 1927, que em sua poesia religiosa, o autor fora influenciado pela solidão - em função do fato de ter ficado órfão muito cedo em sua vida-, por uma impulsividade impossível de governar e pela falta de realização pessoal, o que torna sua poesia confessional, exibindo claramente conflitos psicológicos. No século XX, além de Lacan, Heidegger se referiu várias vezes ao místico que faleceu em 1677 (cf. Enciclopédia Britannica, @2012).

Embora San Angelus esteja posicionado do lado homem, ele também experimenta o gozo místico. Só que, neste caso particular, o gozo místico se confunde com o gozo perverso, pois o que se interpõe entre o sujeito e o seu parceiro (Deus) é o objeto $a$ da fantasia, o olhar de Deus. San Angelus "confunde seu olho contemplativo com o olho com que Deus o olha, isto bem deve, por força, fazer parte do gozo perverso" (Lacan, 1972-1973/1985, p. 102). O gozo perverso de San Angelus corresponde, portanto, à perversão universal (père version), que se especifica na seta que vai de $\$$ até $a$ - na parte inferior das fórmulas.

Pode-se dizer que essa tese não é original, pois desde Freud sabe-se que a sexualidade é perversa. Na verdade foi daí que tudo começou. Quando Freud percebeu que havia uma correlação da neurose com as perversões. É, exatamente, isso que vem em apoio ao que Lacan nomeia de objeto $a$, "pois o $a$ é , justamente, aquilo que, quaisquer que sejam as ditas perversões, está lá como causa delas" (Lacan, 1972-1973/1985, p. 116). 
Na realidade, a perversão universal implica colocar o objeto a da fantasia no lugar do Outro sexo, para poder gozar dele.

Razão pela qual é preciso observar uma diferença importante: por um lado, a perversão universal é do sujeito em direção ao objeto $a$; por outro, diferentemente do neurótico, o gozo do perverso, já mencionado por Lacan em 1963/1998, no texto "Kant com Sade", refere-se ao gozo que o perverso extrai do outro, seu parceiro sexual, dividindo-o, ou seja, identificando-o no lugar de sujeito dividido. Ao fazer o Outro gozar - como Lacan propõe em 1963/1998 - o perverso não coloca seu parceiro do lado da mulher. Ao contrário, o parceiro do perverso está, justamente, na posição de sujeito barrado (\$) e não na de $a$. Ao dividir o sujeito, o perverso quer produzir o sujeito bruto de prazer, visando, portanto, a remoção da barra de \$, como Lacan se exprimia em 1963. E, o Outro que o perverso faz gozar não é seu parceiro, é o Outro da lei que ele procura completar.

Feitas tais considerações, poderíamos ler a representação do gozo do perverso da seguinte forma: em seu ato, o perverso não está na posição de sujeito dividido, mas na posição de $a$, mais de gozar, como objeto causa de gozo para o Outro. Com isso, ao se prestar como esse objeto, ele se faz de instrumento do gozo do Outro e desmente a falta de objeto. Como se dissesse:"o objeto não falta, olha aqui, sou eu, estou aqui para te fazer gozar". O perverso força o seu parceiro a fazer uma coalescência, não entre $\mathrm{S}(\mathbb{A})$ e $a$, mas entre o $a$ e o sujeito bruto do prazer (S). Como dito, o perverso remove a barra do sujeito (S), levando-o a obter um gozo obscuro (cf. Lacan, 1963/1998) $-a \rightarrow \$ \rightarrow$ S.

Mas a representação do gozo do perverso nas fórmulas verifica, com maior clareza, que o que diferencia a neurose da perversão é a estratégia de gozo. Na sua relação com o parceiro, o neurótico mantém a divisão do seu lado, ele tenta tomar no parceiro o objeto que o "complementa" (Lacan, 1968-1969/2008, p. 248) em sua fantasia (o seio, as fezes, o olhar, a voz). A estratégia de gozo do perverso é outra. $O$ sujeito perverso coloca a divisão do lado do parceiro e, do lugar de $a$, se oferece como"suplemento" (Lacan, 1968-1969/2008, p. 248), como instrumento do gozo do Outro, oferecendo à hiância do Outro, o mais-de gozar. Se o sujeito neurótico leva em conta o não-todo, o perverso se posiciona no não-todo para desmentir o próprio não-todo. As fórmulas de Lacan desvelam o que diferencia a estrutura neurótica e a perversa: é a posição que o sujeito ocupa diante do Outro na fantasia, no jogo entre o sujeito e o seu parceiro.

\section{A ética do celibatário.}

Em Televisão, Lacan (1974/1993) propõe uma subdivisão ética na perversão universal e produz um termo que permite estigmatizar essa 
subdivisão:"a ética do celibatário". Ética que elimina o Outro sexo, melhor dizendo, que exclui a mulher como Outro. Interessante notar que tal exclusão não implica o desmentido da castração, pois é perfeitamente possível o sujeito se manter do lado homem excluindo o lado mulher e estar submetido à determinação de que "para todo x, fi de x", ou seja, àquela determinação segundo a qual todos são castrados, inserindo-se na série dos castrados. Para ilustrar essa ética, Lacan toma como exemplo Kant e Montherlant (Lacan, 1974/1993, p. 72).

Kant enuncia o imperativo categórico:"age sempre de tal modo que a máxima de tua ação possa elevar-se à faixa de lei universal" (citado por Lacan, 1963/1998). Para Lacan, nessa máxima está contida uma renúncia, Kant renuncia a qualquer objeto que qualificasse de patológico (pathos), qualquer objeto particular convocado por desejos particulares. Se Kant é um sujeito do desejo, isso decorre do fato de estar referido à lei e, como a lei institui o desejo, ele é desejante. Por outro lado, por renunciar ao pathos, renuncia à relação com o Outro sexo, a mulher.

Montherlant era pedófilo, preso ao gozo fálico do órgão, especialmente o do parceiro. É também o protótipo do que Lacan chama de homossexual. "O homossexual... o homodito pôde bastar-se com a matéria prima bruta do inconsciente" (Lacan, 1973/2003, p. 468). Ele utiliza um neologismo "homodito" (no original, l'hommodit) que reúne o afixo hommo (de homem e de igual) e o substantivo/particípio do verbo dizer, dit (dito). O termo soa como "homem dito". Disso, nossa leitura deriva que aquele que se diz homem, prescinde de uma referência ao lado mulher. Na realidade, com esse neologismo que associa a posição de gozo com a palavra, Lacan chama a atenção para o fato de que a escolha de um parceiro do mesmo sexo tem mais a ver com a relação do sujeito com a linguagem do que com qualquer "aberração sexual".

No contexto de que estamos tratando, o homodito é aquele cujo objeto só não é o mesmo porque, na realidade, encarna o eu ideal do sujeito que metaforizou o $\Phi$, falo simbólico, com sua referência ao falo imaginário: $-\varphi / i(a)$. Em sua escolha, o sujeito não só demonstra estar fixado exclusivamente ao gozo fálico do órgão, como também o busca em um rapaz, tomado justo no momento da puberdade, idade da fixação de seu próprio ideal.É algo que se pode encontrar em André Gide (cf.Lacan, 1958/1998a, pp. 291-315). Justamente, ele escolhia rapazes da idade que ele tinha quando sua tia tentou seduzi-lo, momento traumático do início de sua puberdade. As práticas de Gide eram de toques e masturbação, com uma espécie de duplo idealizado, um eu ideal encarnado, de maneira que o objeto eleito, o rapaz que ele foi, manteve-o ancorado no gozo fálico reduplicado nos jogos masturbatórios em espelho, como Freud já o descrevera quando discutia a questão da homossexualidade masculina, "a masturbação mútua é muitas vezes o único objetivo da relação" (Freud, 1905/2005b, p. 134). Mas diferentemente de Kant e Montherlant, 
Gide mantinha também um outro relacionamento, não exatamente com sua esposa, Madelaine, mas com as cartas que a ela dirigia. Elas eram, para ele, uma outra coisa, e a destruição das cartas promovida por Madelaine em momento de ira, foi terrível para o marido:"Sofro como se ela tivesse assassinado o nosso filho" (Gide, 1918/1951). Madelaine sempre fora o lugar do endereçamento de sua escrita -, lugar das cartas-letra (lettre, em francês, é tanto carta quanto letra) questão que não podemos desenvolver aqui, mas que certamente tem importância na sua economia de gozo por incluir a referência à letra como $a$.

Levantamos a hipótese de que poderíamos representar a posição sexuada de Montherlant nos mesmos moldes daquela de Kant, introduzindo, no entanto, o desdobramento que também descrevemos em Gide: a referência ao falo simbólico positiva $0-\varphi$ (o falo imaginário), na medida em que o parceiro é o eu ideal que vela a castração. Tal desdobramento diferencia-os de Kant, um sujeito neurótico. A ética do celibatário exclui o Outro sexo, quer se eximindo de qualquer escolha de objeto - como em Kant -, quer buscando no outro seu próprio reflexo no espelho - como em Montherlant e em Gide. O parceiro de gozo está em $\Phi$.

\section{O fora-do-sexo.}

Dois anos antes de forjar a expressão "ética do celibatário", em Televisão, Lacan (1974/1993) já havia batizado outra ética, a "ética fora-do-sexo". Lacan depreende-a da philia (amizade grega), que explica da seguinte maneira: os amigos ( $\phi i \lambda \mathrm{ol}$, filoi) se reconhecem entre si e se escolhem uns aos outros em função de se reconhecerem na coragem necessária para "sustentar a relação intolerável com o ser supremo" (Lacan, 19721973/1985, p. 114). Com efeito, "cada um dos seres que estão no mundo só pode se orientar em direção ao ser maior quando confunde seu bem, seu próprio bem, com aquele com o qual resplandece o Ser supremo" ( $p$. 114). A alma é consequência dessa confusão, dessa identificação com o Ser supremo, então Lacan propõe, para pensarmos a philia, o trocadilho que inclui por um lado, o amor da amizade entre homens e, por outro, a alma (almor). $O$ fora-do-sexo se diferencia dos casos anteriores porque aqueles excluem o Outro sexo, enquanto estes - implicados na philia, no amor entre os homens, portanto homossexual-, se amigam visando o almor (a relação com Deus), a partir da alma através da qual a mesma visa a Ele (p. 114). O objeto implicado no almor, relação com Deus, é o $a$, o objeto $a$ que está do lado direito das fórmulas.

4 “Philia' (em grego: $\varphi$ ı $\lambda$ í $\alpha$ transliteração para o latim: philia) retirado do tratado de Ética a Nicômaco, de Aristóteles, o termo é traduzido geralmente como 'amizade'e, às vezes também, como'amor'"' (Encyclopaedia Britannica). 
Lacan reencontra esse modelo no caso Dora (Freud, 1905[1901]/2005), que já não se mesma em Deus, mas no homem que tem a Sra.K. como objeto da causa de seu desejo. O amor das histéricas pelo homem as faz"bancar o homem, por serem por isso, homossexuais ou fora-do-sexo" (Lacan, 1972-1973/1985, p. 113). A homosexualidade aqui não é aquela que vimos no exemplo de Montherlant - homosexualidade que não se relaciona com o lado direito das fórmulas quânticas da sexuação -, mas somente produto de um almor em que elas "se mesmam no Outro sem sabê-lo" (p. 114).

Colette Soler (2008) propõe a seguinte operação para Dora: do lugar de $L \not$, uma mulher dirige-se ao homem, da mesma maneira como o faziam os filoi que se amavam mutuamente, para daí buscar o seu parceiro, o objeto $a$. O que significa a histérica "fora-do-sexo"? Tudo indica que esta é uma maneira de Lacan reformular a questão do objeto na histeria. Qual é o objeto da mulher histérica? O problema começa com Dora. O seu objeto era o homem? A mulher? O Sr. K? A Sra. K? Ela é heterossexual? Homossexual? Como dito, a tese de Lacan aqui não é a da homossexual no sentido de ela desejar sexualmente as mulheres, mas homossexual no sentido de mesmarem-se no homem que, por sua vez, visa o objeto $a$ no almor. Por que dizer que ela é fora-do-sexo? O específico no caso, é que ela se interessa pelo objeto que causa o desejo do Outro, seu homem, mas só o alcança pela mediação dele. A histérica, fora-do-sexo, não é como o celibatário. É num fora-do-sexo que ela vai buscar o objeto a no campo do Outro sexo (Soler, 2008, p. 193), colocando-se, porém, do lado homem das fórmulas. Isso porque há um impossível na relação de $L \not a$ para $a$, tanto que Lacan não introduz nenhuma seta que venha de $L / a$ para $a$, na parte inferior das fórmulas. Para atingir $a$, partindo de $L \not h$, é preciso dar a volta em $\$$.

Em "L'Étourdit",Lacan (1973/2001) chama heterossexual aquele que ama as mulheres: "chamemos heterossexual, por definição, aquele que ama as mulheres, qualquer que seja seu sexo próprio" (p.467). Nas fórmulas quânticas da sexuação, encontramos o sujeito sempre do lado homem, e seu parceiro, se estiver do lado mulher, então, independente do sujeito ser homem ou mulher anatomicamente, se ama a uma mulher tem relação com o Outro sexo, é heterossexual. Eis também porque Dora não é homossexual.

\section{Desejo e gozo.}

Para avançarmos na questão de que trata esse artigo, ou seja, nas contribuições propostas pelo estabelecimento das fórmulas quânticas da sexuação para a distinção entre desejo e gozo, recapitulemos como se articulam. 
Pudemos verificar que San Angelus Silesius é um homem, no sentido da anatomia, que está do lado do todo fálico, na posição de $\$$, e visa a. Entre ele e seu Deus há um objeto, o olhar $\$ \rightarrow a$. Hadewijch e Santa Teresa d'Avila são mulheres, no sentido da anatomia, que estão do lado do não-todo fálico, na posição de $L \not a ́$, experimentam o gozo místico, $S(\mathbb{A})$ : $L, a ́$ $\rightarrow \mathrm{S}(\mathbb{A})$.

Kant e Montherlant são homens, no sentido da anatomia, que estão do lado do todo fálico, na posição de $\$$, buscam no parceiro $\Phi$ o gozo fálico: $\$ \rightarrow \Phi$.

Dora é uma mulher, no sentido da anatomia, que está do lado do não-todo fálico, $L \not h$. Busca no homem uma identificação como sujeito, "banca o homem", passando para a posição de \$. Desse lugar, ela busca

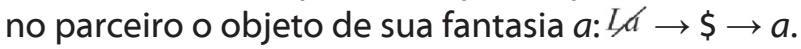

André Gide é um homem, no sentido da anatomia, ele está do lado do todo fálico, \$, e seu parceiro se divide entre os rapazes, os filoi que o mesmam positivando o $\Phi$, e também, as cartas que escrevia para Madelaine declarando o seu amor em referência ao objeto $a$ (as cartas-letras que o representam).

Não há dúvida de que todas as posições que assinalamos a cada sujeito envolvido são posições de gozo. A questão que se coloca agora diz respeito ao desejo. Para verificá-lo, retomemos um texto publicado em 2005 para o que é necessário voltar ao campo da fala e da linguagem em Lacan. Examinemos a relação da perversão com o grafo do desejo que Lacan (1960/1998, p. 831) construiu nos anos de 1958-1959.

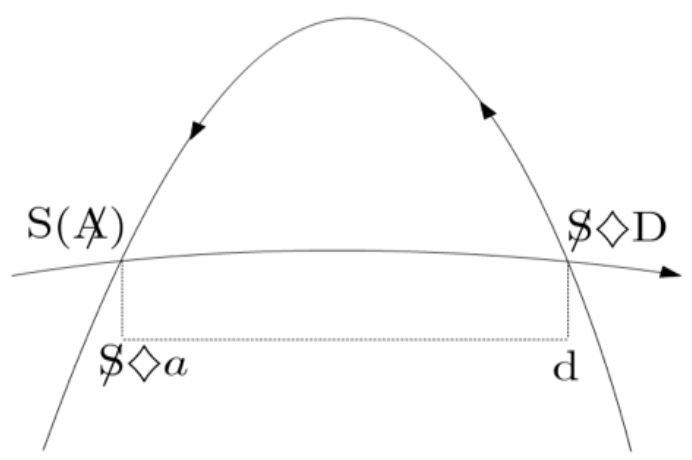

Figura 2. Esquema que retoma a parte superior do grafo do desejo de Lacan (Alberti, 2005, p. 354).

O texto em questão, parte da proposta de que a perversão remonta às origens do desejo e pode promover uma "submissão abjeta ao Outro, 
uma servidão avassaladora" (Lévinas, citado por Queirós, 2002, p. 52), justamente por intermédio dessa origem.

Como sabemos, todo desejo é desejo do Outro, eis a origem mesma do desejo que o amarra a uma posição de gozo original, identificada por Freud de masoquista (Freud, 1924/2006). Orientadas por essa observação, retomamos então a referência de Lacan segundo a qual o perverso "apenas acentua a função do desejo no homem na medida em que ele institui o predomínio, no lugar privilegiado do gozo, do objeto $a$ da fantasia, que ele coloca no lugar do A. A perversão acrescenta a recuperação do $\varphi^{\prime \prime}$ (Lacan, 1960/1998, p. 823) que concerne ao Outro de um modo particular.

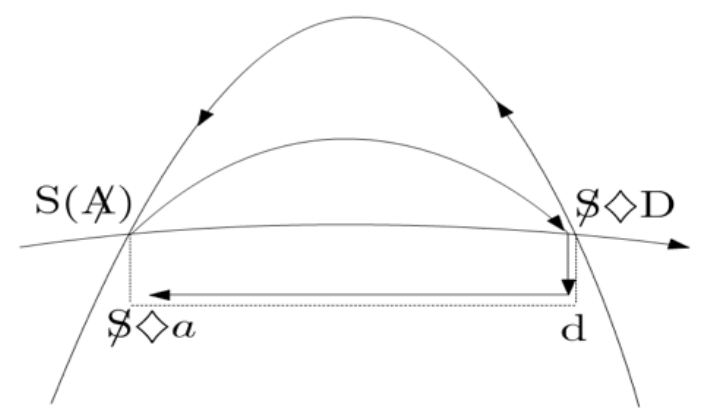

Figura 3. Esquema que retoma a parte superior do grafo do desejo de Lacan, traçado a partir dos desenvolvimentos em Alberti (2005, p. 354).

Para acompanhar tal processo no próprio grafo do desejo (Lacan, 1960/1998), poderíamos descrever um movimento que volta de $S(\mathbb{A})$ que não é atravessado em consequência do desmentido da castração específico da perversão - ao desejo (d), e dali, em direção à fantasia que o desejo constitui, levando à consequência necessária de se ler a fantasia $a<>\$$, quer dizer, ao contrário do que normalmente se lê: $\$<>a$. Porque a castração é insuportável, recua-se diante dela sem, portanto, atravessá-la. Chega-se assim de volta à lógica da pulsão, dela ao desejo determinado pelos desígnios do Outro que, sem serem interrogados, levam ao matema da fantasia pelo caminho inverso daquele que teria tomado o sujeito neurótico que atravessa a castração em S(A). (Alberti, 2005, p. 353)

O preço que o perverso paga por sua Verleugnung - o desmentido da castração -,é o de se ver obrigado a nunca poupar esforços para tentar suprir o Outro com o gozo do qual seria castrado se tal castração não tivesse que ser sempre desmentida. Razão da observação de Lacan de que ele sempre se faz instrumento do gozo do Outro, acima referida (Lacan, 1960/1998, p. 823), o que, aliás, também coloca em causa os objetos 
pulsionais que, conforme corroboram as palavras de Costa (2004, p. 23), são "designativos do objeto de gozo do Outro".

Isso ratifica a observação que Freud já fizera em 1905/2005a, de que o neurótico tem uma maior variabilidade e maior mobilidade, no que se refere ao gozo, enquanto o perverso, ao contrário, fica fixado na mesma posição de gozo, desvelando, assim, uma estereotipia. É a relação com a castração que dá ao neurótico a flexibilidade que o perverso não tem, ou seja, conforme o grafo do desejo: é a possibilidade de atravessar $S(\mathbb{A})$, no grafo do desejo, que leva o neurótico a se questionar, como sujeito, diante de todas as possibilidades de sua relação com o objeto $a(\$<>a)$, ao contrário do perverso, que lê esse matema $(a<>\$)$, fixando o sujeito numa modalidade de gozo.

\section{Neurose e perversão.}

Se voltarmos ao campo do gozo em Lacan, notamos que essa diferença de leitura não desimplica o perverso com o lado direito das fórmulas quânticas da sexuação, pois se parte de uma fantasia que se escreve $a<>\$$, necessariamente articula ambos os lados das fórmulas, o $a$ está do lado direito e o $\$$, do esquerdo. Definitivamente, o perverso apenas desmente o que o neurótico atravessa, a impossibilidade com a qual ele tem que se haver se quiser exercer-se como sujeito do desejo. Retomemos a partir da análise que Lacan pode fazer da fobia do pequeno Hans.

Desde o momento em que aprofunda a relação de objeto entre mãe, criança e falo, Lacan (1956-1957/1995, p. 22) se utiliza do termo complementaridade para distinguir a função do objeto na neurose, em particular, na fobia. Ainda em O Seminário, livro 16, de um Outro ao outro, ao comentar mais uma vez o caso do pequeno Hans, Lacan diz que "o importante aqui não é a função imaginária ou identificatória de Hans ao complemento de sua mãe que é, no fundo, seu grande rival, o falo, mas é de transmutar esse falo ao simbólico pois é aí que ele terá sua eficácia" (Lacan, 1968-1969/2008, p. 313). É, portanto, a referência ao falo imaginário que faz Hans, identificado com ele na relação com a mãe, buscar colmatar a castração dela quando, na realidade, o falo simbólico sustentaria sua posição desejante. Para o sujeito então, em mal de desejo, o objeto fóbico não é somente significante que aglutina em torno de si os afetos que se desligaram das ideias de desejo no momento do recalque secundário (Freud, 1908/2003), mas também a possibilidade de identificar o falo em outro lugar (o cavalo) de maneira a poder evitar a complementaridade angustiante. Por isso a referência de Lacan à placa giratória, tempo no qual o sujeito se mantém antes que possa efetivamente entrar em ação, o pai real que veicula a castração. O objeto da fobia é constituído para 
manter à distância a angústia de castração: “Pensa que é ao exterior do corpo. É por isso que o vê como uma coisa separada, como um cavalo que começa a se levantar e dar coices" (Lacan, 1957/1995, p. 89). Conforme Lacan retoma de Freud (1927/2004), o fetiche - paradigma da perversão - "é ele também certa proteção contra a angústia, e coisa curiosa, a mesma angústia, ou seja, a angústia de castração" (Lacan, 1956-1957/1995, p. 22). Se a fobia vela a estrutura - que inclui o impossível veiculado pela castração -, a perversão "é uma tentativa de elidir a castração dando estatuto de gozo ao objeto" (Lopes, 2008). Então a fobia é uma placa giratória que só se precipita quando a estrutura neurótica se estabelece, seja ela histeria ou neurose obsessiva (Lacan, 1968-1969/2008, p. 298). Daí a placa giratória ser identificada por Lacan também como o tempo que poderia ter produzido uma perversão, caso o falo simbólico não se inscrevesse pela via do pai real.

Na fobia, o gozo é fálico, fora do corpo, porém o sujeito não se autoriza ao gozo, o próprio gozo se torna angústia, falta libido e em seu lugar fica a angústia (Consentino, n.d, p. 96). Na perversão, o sujeito não se angustia. Não é ele quem goza, é o Outro, a quem ele serve, no sentido mesmo da servidão. Se na fobia, chegará o momento em que o objeto de angústia se transmuta em significante da lei do pai, opera-se uma passagem do imaginário ao simbólico a partir do atravessamento da castração do Outro, momento da precipitação da placa giratória.

Na perversão, a lei não se relaciona com o falo, porque este não sofre, como na fobia, tal transmutação. Lembremo-nos da observação de Lacan (1966-1967): se "O ato perverso se situa no nível da questão sobre o gozo, o ato neurótico, mesmo quando referido ao modelo do ato perverso, tem o único fim de sustentar o que nada tem a ver com a questão do ato sexual, a saber, o efeito do desejo" (lição de 7 de junho de 1967, grifo nosso). Tal diferença se vê mais claramente no contexto do contrato masoquista, este demanda a seu parceiro que aja conforme contrato definido pela vontade de gozar que atribui a ele enquanto Outro na cena. É um cenário que é montado, no qual o masoquista apenas busca o gozo do Outro, a questão do desejo não se coloca.

Além disso, se na fobia a questão é o complemento, na perversão trata-se de um suplemento de gozo. Veja-se, por exemplo, a passagem, em que Lacan (1964/1990, p. 155) articula o suplemento às quantidades de energia tais que desenvolvidas por Freud (1895/2004) em seu "Projeto para uma psicologia". Aqui, trata-se de um gozo suplementar. Se o suplemento diz respeito ao gozo, o complemento se articula em referência ao falo. Mas não a qualquer um, e sim, ao falo imaginário que, como o retomamos da referência de Lacan ao caso do pequeno Hans, mantém o sujeito como complemento da mãe, na placa giratória antes de sua definição na estrutura necessariamente neurótica. 
Colette Soler (2008) diz que na neurose o sujeito extrai o objeto do Outro, enquanto que na perversão ele suplementa o Outro com o objeto. Por não suportar o encontro com a castração do Outro, o movimento do perverso é de suplementar o Outro com um gozo.

Nesse ponto retomamos uma questão inicial, considerando as fórmulas quânticas da sexuação, haveria alguma analogia entre a neurose e a perversão? Pode-se dizer que tanto na neurose como na perversão entre o sujeito e o Outro, está o objeto $a$, ou seja, há uma perversão universal. Qual então a especificidade de cada uma das estratégias? O neurótico mantém a divisão do seu lado e vai buscar no Outro - cuja divisão quer velar - o objeto que o complementa em sua fantasia (o seio, as fezes, o olhar, a voz). Dora, como vimos, se homossexualiza no Outro para alcançar o objeto, da posição de $L \not ́$ bu busca, do lado do homem, o sujeito; a mulher obsessiva - dialeto da histeria (Freud, 1909/2005) -, da mesma forma vai se identificar com o homem quando pode desejar - o que nem sempre é o caso... Mas da posição de $L \not a ́$ busca, do lado do homem, o $\Phi$, já que o valor do homem é ser portador do falo. Em ambos os casos, o Outro permanece furado. Em Dora, como vimos, porque busca o objeto que causa seu desejo, homosexualizada, na neurose obsessiva porque jamais o Outro é inteiro ou lhe faltam os objetos ou ele próprio não passa de um deles. Na perversão, o sujeito se coloca na posição de objeto $a$ para assim suplementar o Outro com gozo. A diferença está então no que complementa e no que suplementa (cf. Lacan, 1968-1969/2008, p. 248).

Em 1956-1957, Lacan diz a seguinte frase, que retomamos para nos ajudar a distinguir exatamente o que ocorre então na perversão: com o fetichista "parece-me estarmos diante de um sujeito que nos mostra, com uma rapidez excessiva, sua própria imagem em dois espelhos diferentes" (Lacan, 1956-1957/1995, p. 86). Há um saber sobre a verdade da castração (Lacan, 1966/1998, p. 892), mas isso não o impede de gozar como se ele não soubesse - "eu sei bem, mas mesmo assim", já observava Octave Mannoni (1973). Assim, retoma a observação freudiana de que o fetiche é um compromisso entre o reconhecimento e o desmentido da castração (Freud, 1927/2004).

Conclui-se assim que o gozo perverso não pertence exclusivamente à estrutura perversa. $O$ sujeito pode gozar perversamente orientado, quando neurótico. $\mathrm{O}$ que distingue fundamentalmente o neurótico do perverso é a posição desejante. Com isso retomamos o texto de Freud, "O Fetichismo", para observar que o autor já levantava questões, em 1927, que hoje podemos referir à diferença entre o gozo e o desejo, e que a "imensa maioria dos homens" supera o horror da castração porque tem o desejo perversamente orientado, mas isso os leva a saber fazer com a mulher (Lacan, 16 de novembro de 1976), levando em conta a castração. Quanto à homossexualidade, o que pudemos verificar nos exemplos de Montherlant e Gide é que há efetivamente uma dificuldade em visitar o 
lado mulher, sem referência fálica, o lado direito das fórmulas quânticas da sexuação, excluindo, portanto, o Outro sexo. Na homossexualidade, o gozo está sempre referido ao fálico o que implica, por sua vez, que relacionar-se com parceiros do mesmo sexo ou do outro sexo não especifica a estrutura clínica. No caso Dora, mais do que homossexual, Lacan propõe o fora do sexo, pois não podendo evitar se encontrar originalmente em $L, a$, dirige-se a $\$$, do lado homem, como os $\phi 1 \lambda$ or da Antiguidade, mesmando-se nele quando ele busca em $a$ o objeto que causa seu desejo. O perverso, por sua vez, que também goza perversamente orientado, apaga-se como sujeito no ato perverso, razão de não podermos dizer que então se trata de um sujeito desejante, ele está no lugar da vontade de gozo, de instrumento que suplementa o Outro com gozo, dividindo seu parceiro, fazendo dele sujeito.

Talvez conseguimos contribuir para o aprofundamento das três questões de Freud, identificadas no início. Se há diferenças nas escolhas dos sujeitos é porque a relação sexual é impossível e cada um procurará se exercer como puder diante disso, alguns evitando a questão sobre o desejo, mas todos usufruindo, gozando, como seres marcados pela linguagem.

\title{
Sexuation, desire and jouissance: Between neurosis and perversion
}

\begin{abstract}
This article takes up Freud's three questions proposed in his exceptional text from 1927 entitled "Fetishism", to rethink them from the point of view of Lacan's teaching during the 1970s, known as the field of jouissance. The article makes use of the quantic formulas of sexuation to verify the logical evidence "there is no sexual relation"through the sexual position which individuals can occupy with their partners in the neurotic and perverse structures. We have questioned some variants of the subject with it's partner in relation to jouissance and desire. The article discusses the three types of jouissance checked by Lacan in the subject's relation to the sexual partner, the feminine jouissance - also called supplementary and Other jouissance - , the mystical jouissance and the perverse jouissance. Cases worked by Lacan are revisited to question what distinguishes the neurotic and the perverse, resuming the issues introduced by Freud.
\end{abstract}

Keywords: Sexuation. Desire. Jouissance. Neurosis. Perversion. 


\section{Sexuation, desir et jouissance: entre névrose et perversion}

Resumé: Cet article reprend trois questions lancées par Freud en 1927, dans son texte exceptionnel intitulé «Le fétichisme», pour les repenser à partir de l'enseignement de Lacan des années 1970, connu comme le champ de la jouissance. L'article utilise les formules quantiques de la sexuation afin de vérifier l'évidence logique du « pas de rapport sexuel » dans les positions sexuelles qu'une personne peut occuper avec ses partenaires dans les structures névrotiques et pervers. Nous avons interrogé quelques variantes pour un sujet avec son partenaire par rapport à la jouissance et le désir. L'article évalue les trois types de jouissance proposés par Lacan pour le rapport du sujet à son partenaire sexuel : la jouissance féminine - aussi appelé supplémentaire et Autre jouissance - la jouissance mystique et la jouissance perverse. Nous revisitons quelques cas travaillées par Lacan quant aux distinctions fondamentales entre névrose et perversion, pour reprendre, finalment, les questions introduites par Freud.

Mots-clés : Sexuation. Désir. Jouissance. Névrose. Perversion.

\section{Sexuación, deseo y goce: entre neurosis y perversión}

Resumen : Este artículo parte de tres preguntas del texto de Freud de 1927, llamado "Fetichismo", para reflexionar sobre ellas desde el punto de vista de la enseñanza de Lacan en la década de 1970, conocida como el campo del goce. El artículo hace uso de las fórmulas cuánticas de la sexuación, para comprobar la evidencia lógica del "no hay relación sexual" en las posición sexual que un sujeto puede tener con su pareja, en las estructuras neuróticas y perversas. Hemos cuestionado algunas variantes de un sujeto con su pareja en relación al goce y al deseo. El artículo analiza los tres tipos de goce propuestos por Lacan para la relación del sujeto con su pareja sexual: el goce femenino - también llamado complementar y goce Otro -, el goce místico

y el goce perverso. Se revisita los casos trabajados por Lacan para cuestionar lo que distingue fundamentalmente la neurosis de la perversión, para retomar, las cuestiones introducidas por Freud.

Palabras clave: Sexuación. Deseo. Goce. Neurosis. Perversión. 


\section{Referências}

Alberti, S. (2005). A perversão, o desejo e a pulsão. Revista Mal-estar e subjetividade, 5(2), 341-360.

Consentino, J. C. (n.d.). Fobia: nos limites do saber. Revista da Escola Letra Freudiana, 24(3). Recuperado de www.escolaletrafreudiana.com.br/UserFiles/110/File/ artigos/.../014.p...

Costa, A. (2004). Iniciação e marcas. In Associação de Psicanálise de Porto Alegre, Adolescência: um problema de fronteiras (pp. 21-27). Porto Alegre, RS: APPOA.

Angelus Silesius. (@2012). In Enciclopédia Britannica. Recuperado de http://www. britannica.com/EBchecked/topic/24578/Angelus-Silesius

Freud, S. (1969). Aufklärungen, Anwendungen, Orientierungen. Vorlesung 34. In Studienausgabe (Vol. 1, pp. 566-585). Frankfurt: S. Fischer Verlag. (Trabalho original publicado em 1933 [1932])

Freud, S. (2004). Sobre la más generalizada degradación de la vida amorosa (Contribuciones de la Psicología del amor, II). In S. Freud, Obras completas (Vol. 11, pp. 169-173). Buenos Aires, Argentina: Amorrortu. (Trabalho original publicado em 1912)

Freud, S. (2004). Fetichismo. In S. Freud, Obras completas (vol. 19, pp. 141-147). Buenos Aires, Argentina: Amorrortu. (Trabalho original publicado em 1927)

Freud, S. (2004). La Feminidad. Conferência 33. Nuevas conferencias de introducción al psicoanálisis. In S. Freud, Obras completas (Vol. 22, pp. 104-125). Buenos Aires, Argentina: Amorrortu. (Trabalho original publicado em 1933 [1932])

Freud, S. (2005a). Fragmento de análisis de un caso de histeria. In S. Freud, Obras completas (Vol. 7, pp. 1-98). Buenos Aires, Argentina: Amorrortu. (Trabalho original publicado em 1905)

Freud, S. (2005b). Tres ensayos de teoría sexual. In S. Freud, Obras completas (Vol. 7, pp. 109-223). Buenos Aires, Argentina: Amorrortu. (Trabalho original publicado em 1905)

Freud, S. (2005c). Tótem e tabu. Algumas concordâncias em la vida anímica de los selvajes e de los neuróticos. In S. Freud, Obras completas (Vol. 13, pp. 13-193). Buenos Aires, Argentina: Amorrortu. (Trabalho original publicado em 1912-1913) 
Freud, S. (2006). Pulsiones y destinos de pulsión. In S. Freud, Obras completas (Vol. 14, pp. 105-113). Buenos Aires, Argentina: Amorrortu. (Trabalho original publicado em 1915)

Freud, S. (2006). Pegan a un niño. Contribución al conocimiento de la génesis de las perversiones sexuales. In S. Freud, Obras completas (Vol. 17, pp. 173-177). Buenos Aires, Argentina: Amorrortu. (Trabalho original publicado em 1919)

Freud, S. (2006). Más allá del pricipio de placer. In S. Freud, Obras completas (Vol. 18, pp. 1-127). Buenos Aires, Argentina: Amorrortu. (Trabalho original publicado em 1920)

Freud, S. (2006). El yo y el ello. In S. Freud, Obras completas (Vol. 19, 2006, pp. 1-63). Buenos Aires, Argentina: Amorrortu. (Trabalho original publicado em 1923)

Gide, A. (1951). Journal, 22 novembre 1918. In A. Gide, Nouveaux prétextes: réflexions sur quelques points de littérature et de morale (5a ed.). Paris: Mercure de France.

Jones, E. (1955). Sigmund Freud: Life and work (Vol. 2). London, UK: Hogarth.

Lacan, J. (1977). Discussion après l'aprésentation de M. Ritter. Lettres de l'École Freudienne, (21).

Lacan, J. (1985). O Seminário. Livro 20: mais, ainda. Rio de Janeiro, RJ: Zahar. (Trabalho original publicado em 1972-1973)

Lacan, J. (1990). O Seminário. Livro 11: os quatro conceitos fundamentais da psicanálise. Rio de Janeiro, RJ: Zahar. (Trabalho original publicado em 1964)

Lacan, J. (1993). Televisão. Rio de Janeiro, RJ: Zahar. (Trabalho original publicado em 1974)

Lacan, J. (1995). O Seminário. Livro 4: a relação de objeto. Rio de Janeiro: Zahar. Trabalho original publicado em 1956-1957)

Lacan, J. (1998a). Juventude de Gide ou a letra e o desejo. In J. Lacan, Escritos (pp. 749775). Rio de Janeiro, RJ: Zahar. (Trabalho original publicado em 1958)

Lacan, J. (1998b). A significação do falo (Die Bedeutung des Phallus). In J. Lacan, Escritos (pp. 692-703). Rio de Janeiro, RJ: Zahar. (Trabalho original publicado em 1958)

Lacan, J. (1998). Subversão do sujeito e dialética do desejo no inconsciente freudiano. In J. Lacan, Escritos (pp. 807-842). Rio de Janeiro, RJ: Zahar. (Texto original publicado em 1960) 
Lacan, J. (1998). Kant com Sade. In J. Lacan, Escritos (pp. 776-806). Rio de Janeiro, RJ: Zahar. (Texto original publicado em 1963)

Lacan, J. (2001). L'Étourdit. In J. Lacan, Autres écrits (pp. 449-496). Paris, France: Seuil. (Trabalho original publicado em 1973)

Lacan, J. (2003). O aturdito. In J. Lacan, Outros escritos (pp. 448-497). Rio de Janeiro: J. Zahar. (Trabalho original publicado em 2003)

Lacan, J. (2005). O Seminário. Livro 10: a angústia. Rio de Janeiro, RJ: Zahar. (Trabalho original publicado em 1962-1963)

Lacan, J. (2007). O Seminário. Livro 23: o sinthoma. Rio de Janeiro, RJ: Zahar. (Trabalho original publicado em 1975-1976)

Lacan, J. (2008). O Seminário. Livro 16: de um Outro ao outro. Rio de Janeiro, RJ: Zahar. (Trabalho publicado em 1968-1969)

Lacan, J. (1973-1974). Le Séminaire. Livre 21: Les non dupes errent. Inédito.

Lacan, J. (1976-1977). Le Séminaire. Livre 24: L’insu que sait de l'une bévue s’aile à mourre. Inédito.

Lopes, A. C. D. (2008). Fobia, perversão e metáfora paterna. Revista Eletrônica do Núcleo Sephora. Recuperado de http://www.nucleosephora.com/asephallus/ numero_07/artigo_02_port.html

Mannoni, O. (1973). Eu sei, mas mesmo assim... In O. Mannoni, Chaves para o imaginário (pp. 9-34). Petrópolis, RJ: Vozes.

Martinho, M. H. (2011). Perversão: um fazer gozar (Tese de Doutorado). Programa de Pós-graduação em Psicanálise, Instituto de Psicologia, Universidade do Estado do Rio de Janeiro, RJ.

Queiroz, E. F. (2002). Perversão e alteridade. Psicologia Clínica, 14(2), 43-54.

Soler, C. (2008). La maldición sobre el sexo. Buenos Aires, Argentina: Manantial.

Tesone, J. E. (2008). O divino gozo: o narcisismo feminino e os místicos. Revista Brasileira de Psicanálise, 42(4). Recuperado de http://pepsic.bvsalud.org/scielo. php?script=sci_arttext\&pid=S0486-641X2008000400016) 
Sonia Alberti, professora associada do Instituto de Psicologia da Universidade do Estado do Rio de Janeiro. Procientista e membro do colegiado do Programa de Pósgraduação em Psicanálise/UERJ, pesquisadora do CNPq, psicanalista membro da Escola de Psicanálise dos Fóruns do Campo Lacaniano. Endereço para correspondência: Rua João Afonso, 60 casa 22. CEP 22261-040, Rio de Janeiro, RJ, Brasil. Endereço eletrônico: sonialberti@gmail.com

Maria Helena Martinho, professora dos cursos de mestrado e de especialização em psicanálise da Universidade Veiga de Almeida, coordenadora e supervisora clínica do SPA/UVA, professora e supervisora do curso de especialização em psicologia clínica da PUC-Rio. Psicanalista, membro da Escola de Psicanálise dos Fóruns do Campo Lacaniano. Doutora e Mestre pelo Programa de Pós-graduação em Psicanálise/IP/UERJ. Endereço para correspondência: Av. Adolpho de Vasconcelos, 245/1212. CEP 22793380, Rio de Janeiro, RJ, Brasil. Endereço eletrônico: mhmartinho@yahoo.com.br

Recebido: 23/01/2012

Aceito: $17 / 10 / 2012$ 